\title{
Time trends in organ donation after neurologic determination of death: a cohort study
}

\author{
Andreas H. Kramer MD MSc, Ryan Baht RN BSN, Christopher J. Doig MD MSc
}

\section{Abstract}

Background: The cause of brain injury may influence the number of organs that can be procured and transplanted with donation following neurologic determination of death. We investigated whether the distribution of causes responsible for neurologic death has changed over time and, if so, whether this has had an impact on organ quality, transplantation rates and recipient outcomes.

Methods: We performed a cohort study involving consecutive brain-dead organ donors in southern Alberta between 2003 and 2014. For each donor, we determined last available measures of organ injury and number of organs transplanted, and compared these variables for various causes of neurologic death. We compared trends to national Canadian data for 2000-2013 (2000-2011 for Quebec).

Results: There were 226 brain-dead organ donors over the study period, of whom 100 (44.2\%) had anoxic brain injury, 63 (27.9\%) had stroke, and $51(22.6 \%)$ had traumatic brain injury. The relative proportion of donors with traumatic brain injury decreased over time $(>30 \%$ in $2003-2005$ v. $6 \%-23 \%$ in $2012-2014)(p=0.004)$, whereas that with anoxic brain injury increased $(14 \%-37 \%$ v. $46 \%-80 \%$, respectively) $(p<0.001)$. Nationally, the annual number of brain-dead donors with traumatic brain injury decreased from 4.4 to less than 3 per million population between 2000 and 2013, and that with anoxic brain injury increased from 1.1 to 3.1 per million. Donors with anoxic brain injury had higher concentrations of creatinine, alanine aminotransferase and troponin $\mathrm{T}$, and lower $\mathrm{P}_{\mathrm{a}} \mathrm{O}_{2} / \mathrm{F}_{1} \mathrm{O}_{2}$ and urine output than donors with other diagnoses. The average number of organs transplanted per donor was 3.6 with anoxic brain injury versus 4.5 with traumatic brain injury or stroke $(p=0.002)$.

Interpretation: Anoxic brain injury has become a leading cause of organ donation after neurologic determination of death in Canada. Organs from donors with anoxic brain injury have a greater degree of injury, and fewer are transplanted. These findings have implications for availability of organs for transplantation in patients with end-stage organ failure.

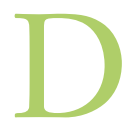
espite the emergence of organ donation after cardiocirculatory determination of death, donation after neurologic determination of death remains the most common source of organs for transplantation across the world. Several studies performed in various countries have shown that the number of brain-injured patients who progress to neurologic determination of death has remained stagnant or even decreased over time..$^{1-7}$ This temporal trend may be most pronounced among patients with traumatic brain injury. ${ }^{1,6,7}$ Advances in injury prevention, resuscitation and supportive care are likely contributing factors. ${ }^{1,8-12}$

In contrast, the proportion of cases of cardiac arrest in which bystander cardiopulmonary resuscitation, automated external defibrillation and advanced cardiac life support lead to return of spontaneous circulation is increasing, such that more patients with anoxic brain injury are admitted to intensive care units than was previously the case. ${ }^{13-16}$ In some people resuscitated from a cardiac arrest, ischemic injury to the brain is sufficiently severe to cause progression to neurologic determination of death. ${ }^{17}$ Apart from causing anoxic brain injury, cardiac arrest may also induce ischemic injury to other organs. In patients who progress to neurologic determination of death, this may reduce the number of organs available for donation and transplantation. When injured and poorly functioning organs are transplanted, graft function in recipients may be delayed or even permanently impaired.

Competing interests: Andreas Kramer is the Medical Director of the Southern Alberta Organ and Tissue Donation Program and a member of the Canadian Blood Services Deceased Donation Advisory Committee. Christopher Doig is the former Medical Lead for the Canadian Council for Donation and Transplantation.

This article has been peer reviewed.

Correspondence to: Andreas Kramer, Andreas.Kramer@ AlbertaHealthServices.ca

CMAJ Open 2017. DOI:10.9778/cmajo.20160093 
We performed a cohort study among consecutive braindead donors in southern Alberta to determine whether the distribution of causes responsible for neurologic death has changed (primary outcome) and, if so, whether this has had an impact on organ quality, transplantation rates and recipient outcomes (secondary outcomes). Using data from the Canadian Institute of Health Information (CIHI), we also assessed trends in the cause of neurologic death and number of organs transplanted per donor across Canada.

\section{Methods}

\section{Setting}

A comprehensive clinical information system (ALTRABase) is used to manage all organ donation referrals in southern Alberta and enables linkage of donor and recipient data. Donor management is in accordance with national guidelines, which are incorporated directly into a region-wide electronic order set. ${ }^{18}$ In every case, solid organs are routinely offered to transplantation programs across the country and, when no suitable recipient is found in Canada, to the United Network for Organ Sharing. Kidney and pancreas transplantation is performed locally, and liver, lung, heart and small-bowel allografts are transported to other centres.

\section{Design}

Using prospectively collected data, we identified consecutive patients who progressed to neurologic determination of death between 2003 (earliest year for which reliable data were available) and 2014 and whose surrogate decision-makers consented to organ donation. The causes of neurologic death were categorized as traumatic brain injury, anoxic brain injury, stroke (subarachnoid hemorrhage, spontaneous intracerebral hemorrhage, ischemic stroke or cerebral venous thrombosis) and other causes. This determination was made by a specialist in neurocritical care (A.K.) based on review of medical records and neuroimaging, without coinciding knowledge regarding organs procured and transplanted. Patients were classified as having anoxic brain injury if there was documentation of a preceding cardiac arrest in the medical record. Patients with cardiac arrest in the context of another type of brain injury were categorized as having anoxic brain injury if the arrest lasted longer than 5 minutes. The rationale was twofold: first, 5 minutes is the approximate time after which permanent ischemic injury to the brain becomes possible. ${ }^{19}$ Second, although the original cause of the brain injury might have been an equally or more important factor causing progression to neurologic determination of death, the concomitant cardiac arrest had the potential to perpetuate organ injury. Significant sustained organ dysfunction is unusual simply from prolonged hypoxemia or a brief cardiac arrest.

For each donor, we determined the following measures of organ injury: last available concentration of creatinine, urea, alanine aminotransferase and bilirubin, average urine output over the 3 hours preceding organ procurement, international normalized ratio, peak troponin $\mathrm{T}$ concentration, ejection fraction by echocardiography and last ratio relating the partial pressure of oxygen to the inhaled fraction of oxygen $\left(\mathrm{P}_{\mathrm{a}} \mathrm{O}_{2} / \mathrm{F}_{1} \mathrm{O}_{2}\right)$, performed in a standardized fashion, with $\mathrm{F}_{1} \mathrm{O}_{2} 100 \%$ and positive end-expiratory pressure $5 \mathrm{~mm} \mathrm{Hg}$. These tests are performed routinely in all brain-dead organ donors.

A secondary outcome was whether organ function was impaired among recipients of grafts from donors with anoxic brain injury compared to other causes. For recipients of kidney transplants from brain-dead donors in 2009-2014, we evaluated the following outcomes: patient and graft survival, delayed graft function, and creatinine concentration at discharge and at 1 year. This time frame was chosen because a provincial electronic health record system became available in Alberta in 2009, enabling detailed follow-up of recipient and kidney graft function. We defined and analyzed delayed graft function in 2 separate ways: 1) as the temporary need for intermittent hemodialysis in the week following transplantation and 2) as "functional" delayed graft function, namely, need for dialysis or failure of the creatinine concentration to decrease by $10 \%$ or more on 3 or more consecutive days during the week following transplantation. ${ }^{20}$ Machine perfusion of kidney grafts between the time of procurement and transplantation was not used. Because liver transplantation, lung transplantation and heart transplantation are not performed at our centre, outcomes in recipients could not be determined.

\section{Sources of data}

Clinical information relevant to organ donors is entered by donor coordinators directly into ALTRABase in all organ donation cases. This includes vital signs, laboratory data and diagnostic imaging results. Similarly, relevant recipient information is entered into the database by transplantation coordinators. Each file is reviewed as part of a regular qualityassurance process to ensure that data are complete.

To examine trends in the cause of neurologic death and number of organs transplanted per donor, we obtained data from CIHI for 2000-2013; national data for 2014 were not available at the time of our analysis. The registry includes data from all 10 provinces and 3 territories. Data for Quebec for 2012-2013 were not available. Brain-dead donors and their cause of death are reported to the Canadian Organ Replacement Registry (managed by CIHI) by individual provincial organ donation agencies. We clustered diagnostic codes in the registry database for patients with neurologic determination of death into the following categories to match, as much as possible, our local data: traumatic brain injury ("trauma," "motor vehicle collision," "gunshot"), anoxic brain injury ("anoxic," "CO poisoning," "asthma"), stroke ("stroke," "ruptured cerebral aneurysm," "spontaneous intracranial haemorrhage") and other ("overdose," "primary CNS tumour," "CNS infection," "intracranial event," "SIDS," "unknown," "other," "cerebral edema"). The registry assigns only 1 code per donor. It was impossible to know whether patients with traumatic brain injury, stroke or other causes of neurologic death (e.g., overdose) may have also had a cardiac arrest. We therefore expected that the proportion categorized as having anoxic brain injury would be smaller in the Canadian Organ Replacement Registry database than in our local data set. Furthermore, some patients with traumatic brain injury, anoxic brain injury or stroke may 
have been categorized simply as having "cerebral edema." It was therefore to be expected that there would be more patients with "other" causes of neurologic death in the registry data set.

To protect privacy, $\mathrm{CIHI}$ regulations preclude release of data when there are fewer than 5 patients per data cell. We therefore clustered data into 3-year periods except for 2012-2013 (2 years).

\section{Statistical analysis}

We used $\chi^{2}$ analysis or the Fisher exact test, as appropriate, to compare categorical variables. We used analysis of variance and Mann-Whitney $\mathrm{U}$ tests to compare continuous variables, with adjustments for multiple comparisons using the Tukey test. $^{21}$ The Cochrane-Armitage test was used to determine the significance of temporal trends. ${ }^{22}$ In assessing the association between cause of neurologic death and number of organs transplanted per donor, we used multivariable ordinal regression to adjust for confounders, including donor age, sex, body mass index, presence of preexisting hypertension or diabetes, use of methylprednisolone or levothyroxine, and presence of positive viral serology (HIV or hepatitis B or C).

\section{Ethics approval}

The Conjoint Health Research Ethics Board at the University of Calgary approved this research.

\section{Results}

\section{Temporal trends in cause of neurologic death}

Between 2003 and 2014 there were 226 brain-dead organ donors in southern Alberta; 100 (44.2\%) had anoxic brain injury, 63 (27.9\%) had stroke, 51 (22.6\%) had traumatic brain injury, and $12(5.3 \%)$ progressed to neurologic death due to other causes. Of the 100 donors with anoxic brain injury, 16 had another, coexisting form of brain injury. Prolonged cardiac arrest occurred in 7 donors with stroke and 9 with traumatic brain injury (these donors were categorized as having anoxic brain injury). The rate of consent for organ donation was $71.9 \%, 73.2 \%$ and $83.6 \%$ among patients with neurologic death due to anoxic brain injury, stroke and traumatic brain injury, respectively $(p=0.4)$ and did not change over time.

The relative proportion of brain-dead donors with anoxic brain injury increased over time, from as low as 14\% in 2004 to as high as $80 \%$ in $2013(p<0.001)$ (Figure 1$)$. In contrast, the proportion with traumatic brain injury gradually decreased over the study period, from about $30 \%$ in $2003-2005$ to as low as $6 \%-7 \%$ in $2013-2014$ ( $p=0.004)$. The proportion with stroke remained relatively unchanged.

Causes of cardiac arrest were classified as follows: overdose 24 cases (24\%), respiratory 20 (20\%), traumatic 15 (15\%), primary cardiac 13 (13\%), neurologic 10 (10\%), suicide by hanging $6(6 \%)$, carbon monoxide poisoning 3 (3\%), drowning 3 (3\%), pulmonary embolism $3(3 \%)$, anaphylaxis 1 (1\%), sepsis $1(1 \%)$ and unknown 1 (1\%).

\section{Organ injury}

Characteristics of the donors with anoxic brain injury, traumatic brain injury and stroke are compared in Table 1 . At least 1 kidney was transplanted from 84 (84\%), 49 (96\%) and $53(84 \%)$ of the donors with anoxic brain injury, traumatic brain injury and stroke, respectively $(p=0.1)$. Donors with

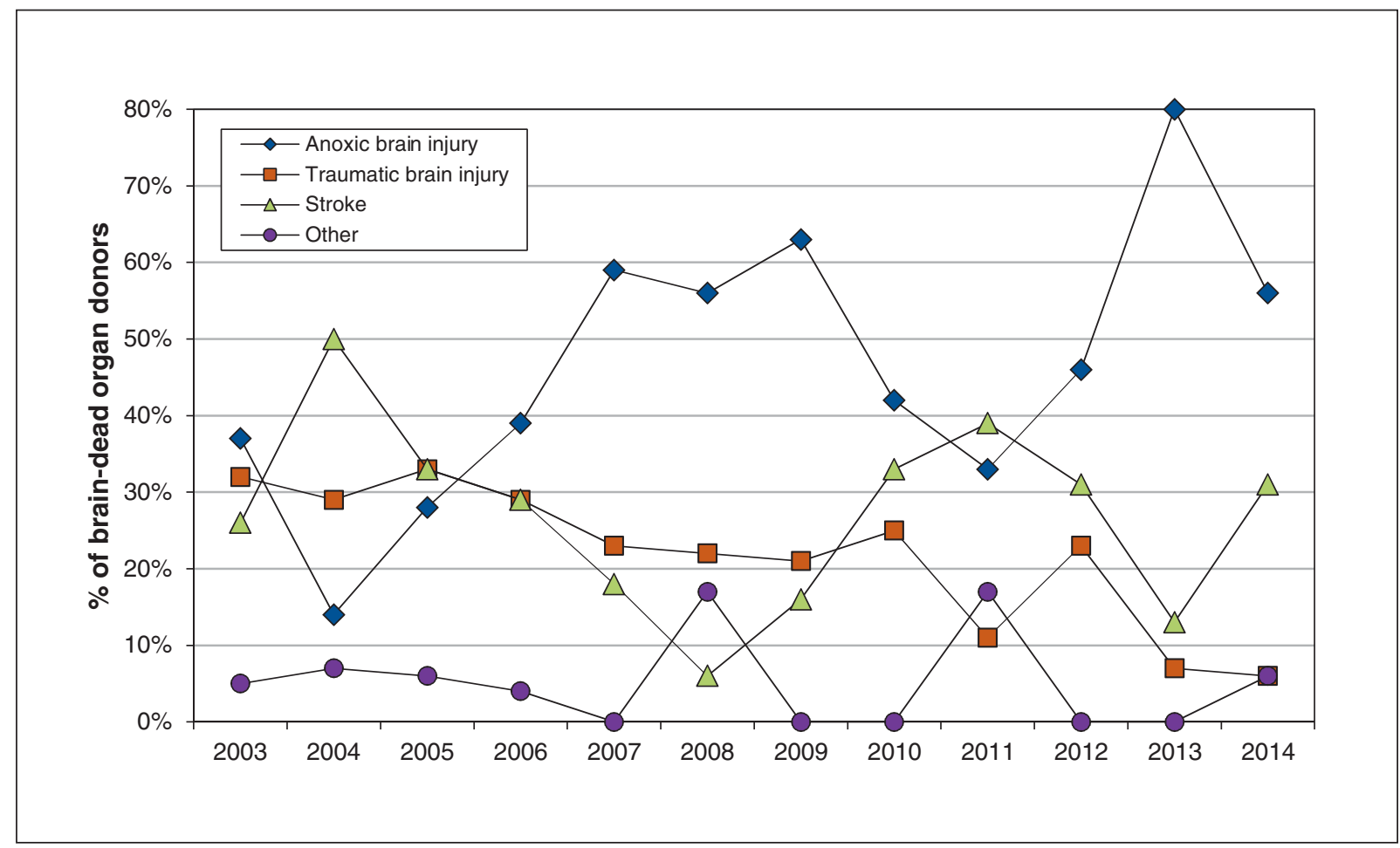

Figure 1: Temporal trends in the relative distribution of causes of neurologic death (brain death) in deceased organ donors in southern Alberta, 2003-2014. 


\section{OPEN}

Research

anoxic brain injury had higher creatinine and urea concentrations and lower urine output than did donors with traumatic brain injury or stroke. Among donors with anoxic brain injury, there was a significant association between the duration of cardiac arrest and the last available creatinine concentration $(p=0.03)$.

Table 1: Characteristics of organ donors and organ transplantation by cause of donor brain death in southern Alberta, 2003-2014

\begin{tabular}{|c|c|c|c|}
\hline \multirow[b]{2}{*}{ Characteristic } & \multicolumn{3}{|c|}{ Cause of brain death } \\
\hline & $\begin{array}{l}\text { Anoxic brain injury } \\
\qquad(n=100)\end{array}$ & $\begin{array}{c}\text { Traumatic brain } \\
\text { injury } \\
(n=51)\end{array}$ & $\begin{array}{l}\text { Stroke* }^{*} \\
(n=63)\end{array}$ \\
\hline Age, median (IQR), yr & $35(23-52)$ & $25(20-42) \dagger$ & $53(39-59) \dagger$ \\
\hline \multicolumn{4}{|l|}{ Sex, no. (\%) } \\
\hline Female & $47(47)$ & $20(39)$ & $32(51)$ \\
\hline Male & $53(53)$ & $31(61)$ & $31(49)$ \\
\hline Body mass index, median (IQR) & $35(25-47)$ & $30(25-35)$ & $34(24-43)$ \\
\hline No. $(\%)$ who were expanded-criteria donors $\ddagger$ & $12(12) \S$ & $6(12) \S$ & $24(38)$ \\
\hline $\begin{array}{l}\text { No. }(\%) \text { with positive result on viral serological } \\
\text { testing (HIV, hepatitis B or C) }\end{array}$ & $6(6)$ & $3(6)$ & $6(10)$ \\
\hline \multicolumn{4}{|l|}{ No. of organs transplanted } \\
\hline Median (IQR) & $4(2.5-5)$ & $4(3-6) \dagger$ & $5(3-6) \dagger$ \\
\hline Mean \pm standard deviation & $3.6 \pm 1.9$ & $4.5 \pm 1.8 \dagger$ & $4.5 \pm 2.2 \dagger$ \\
\hline \multicolumn{4}{|l|}{ Kidney } \\
\hline Creatinine level, median (IQR), $\mu \mathrm{mol} / \mathrm{L}$ & $86(64-140)$ & $75(52-96) \dagger$ & $66(50-83) \dagger$ \\
\hline Urea level, median (IQR), mmol/L & $6.6(4.8-9.9)$ & $4.8(3.6-6.3) \dagger$ & $4.2(3.2-7.3)$ \\
\hline Urine output, median (IQR), $\mathrm{mL} / \mathrm{h}$ & $65(30-125)$ & $125(63-200) \dagger$ & $100(45-175) \dagger$ \\
\hline $\begin{array}{l}1 \text { or } 2 \text { kidneys transplanted, no. (\%) of } \\
\text { donors }\end{array}$ & $84(84)$ & $49(96)$ & $53(84)$ \\
\hline \multicolumn{4}{|l|}{ Liver } \\
\hline $\begin{array}{l}\text { Alanine aminotransferase level, median } \\
(\mathrm{IQR}), \text { units/L }\end{array}$ & $107(59-283)$ & $34(21-54) \dagger$ & $23(14-42) \dagger$ \\
\hline $\begin{array}{l}\text { International normalized ratio, median } \\
\text { (IQR) }\end{array}$ & $1.3(1.2-1.4)$ & $1.2(1.1-1.3)$ & $1.2(1.1-1.3) \dagger$ \\
\hline Bilirubin level, median (IQR), $\mu \mathrm{mol} / \mathrm{L}$ & $8(5-13)$ & $10(7-16)$ & $8(6-12)$ \\
\hline Transplanted, no. (\%) of donors & $81(81)$ & $47(92)$ & $54(86)$ \\
\hline \multicolumn{4}{|l|}{ Lung } \\
\hline $\mathrm{P}_{\mathrm{a}} \mathrm{O}_{2} / \mathrm{F}_{1} \mathrm{O}_{2}$ (last $\mathrm{O}_{2}$ challenge), median (IQR) & $251(120-370)$ & $328(218-407) \dagger$ & $316(227-394) \dagger$ \\
\hline 1 or 2 lungs transplanted, no. (\%) of donors & $22(22)$ & $21(41) \emptyset$ & $34(54) \emptyset$ \\
\hline \multicolumn{4}{|l|}{ Heart } \\
\hline $\begin{array}{l}\text { Troponin T level, median (IQR), ng/mL } \\
\text { (low-sensitivity assay, before 2011) }\end{array}$ & $0.30(0.04-0.83)$ & $0.15(0.03-0.40) \dagger$ & $0.07(0.03-0.32) \dagger$ \\
\hline $\begin{array}{l}\text { Troponin T level, median (IQR), ng/L } \\
\text { (high-sensitivity assay, as of 2011) }\end{array}$ & $311(65-1121)$ & $33(9-62)$ & $14(5-116)$ \\
\hline Ejection fraction, median (IQR), \%** & $55(40-60)$ & $54(40-60)$ & $60(54-64)$ \\
\hline Transplanted, no. (\%) of donors & $30(30)$ & $19(37)$ & $23(36)$ \\
\hline \multicolumn{4}{|l|}{ Pancreas } \\
\hline Whole transplanted, no. (\%) of donors & $20(20)$ & $17(33)$ & $14(22)$ \\
\hline Islet cells transplanted, no. (\%) of donors & $20(20)$ & $6(12)$ & $20(32)$ \\
\hline \multicolumn{4}{|c|}{ 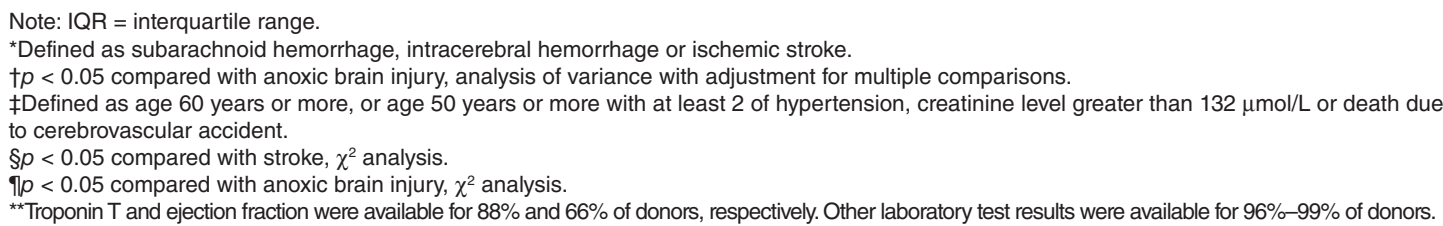 } \\
\hline
\end{tabular}


The liver was transplanted from 81 (81\%), 47 (92\%) and $54(86 \%)$ of the donors with anoxic brain injury, traumatic brain injury and stroke, respectively $(p=0.2)$. The median alanine aminotransferase level was significantly higher in the donors with anoxic brain injury than in those with other diagnoses. The international normalized ratio was significantly higher in the donors with anoxic brain injury than in those with stroke $(p<0.05)$.

At least 1 lung was transplanted from 22 (22\%), 21 (41\%) and $34(54 \%)$ of the donors with anoxic brain injury, traumatic brain injury and stroke, respectively $(p<0.001)$. The last available $\mathrm{P}_{\mathrm{a}} \mathrm{O}_{2} / \mathrm{F}_{\mathrm{I}} \mathrm{O} 2$ was significantly lower in the donors with anoxic brain injury than in those with traumatic brain injury or stroke $(p<0.05)$.

The heart was transplanted from 30 (30\%), 19 (37\%) and $23(36 \%)$ of the donors with anoxic brain injury, traumatic brain injury and stroke, respectively $(p=0.6)$. Troponin $\mathrm{T}$ concentrations were significantly higher among the donors with anoxic brain injury than among those with traumatic brain injury or stroke $(p<0.05)$, but ejection fraction did not differ between the groups.

\section{Organs per donor}

A mean of 3.6 organs were transplanted from donors with anoxic brain injury, compared with 4.5 from those with traumatic brain injury or stroke $(p=0.002)$. In multivariable anal- ysis, anoxic brain injury remained an independent predictor of fewer organs transplanted per donor (odds ratio for more organs procured and transplanted when cause of death was traumatic brain injury or stroke rather than anoxic brain injury $=2.1$ [interquartile range $1.3-3.4$ ]; $p=0.003$ ). The peak mean number of organs transplanted per donor was 4.5-4.6 in 2005-2006, compared with 3.4-3.8 in 2012-2014. However, this change was not statistically significant $(p=0.3)$.

When the analysis was restricted to donors with anoxic brain injury, there was an inverse relation between duration of cardiac arrest and number of organs procured per donor: the mean number of organs transplanted was 4.0 when cardiac arrest lasted less than 30 minutes, compared with 3.5 when it lasted 30-59 minutes and 2.6 when it lasted 60 minutes or longer ( $p=0.04$ for comparison of $\geq 60 \mathrm{~min} \mathrm{v}$. $<60 \mathrm{~min}$ ).

\section{Kidney recipient outcomes}

Between 2009 and 2014, 145 patients received kidney transplants from local brain-dead donors. The cause of neurologic death was anoxic brain injury, traumatic brain injury or stroke in 143 cases (98.6\%). The rate of delayed graft function was lowest among recipients of kidneys from donors with traumatic brain injury and highest among recipients of kidneys from donors with stroke; however, these differences were not statistically significant ( $p=0.2$ ) (Table 2). Creatinine concentrations throughout the week following transplantation, at the

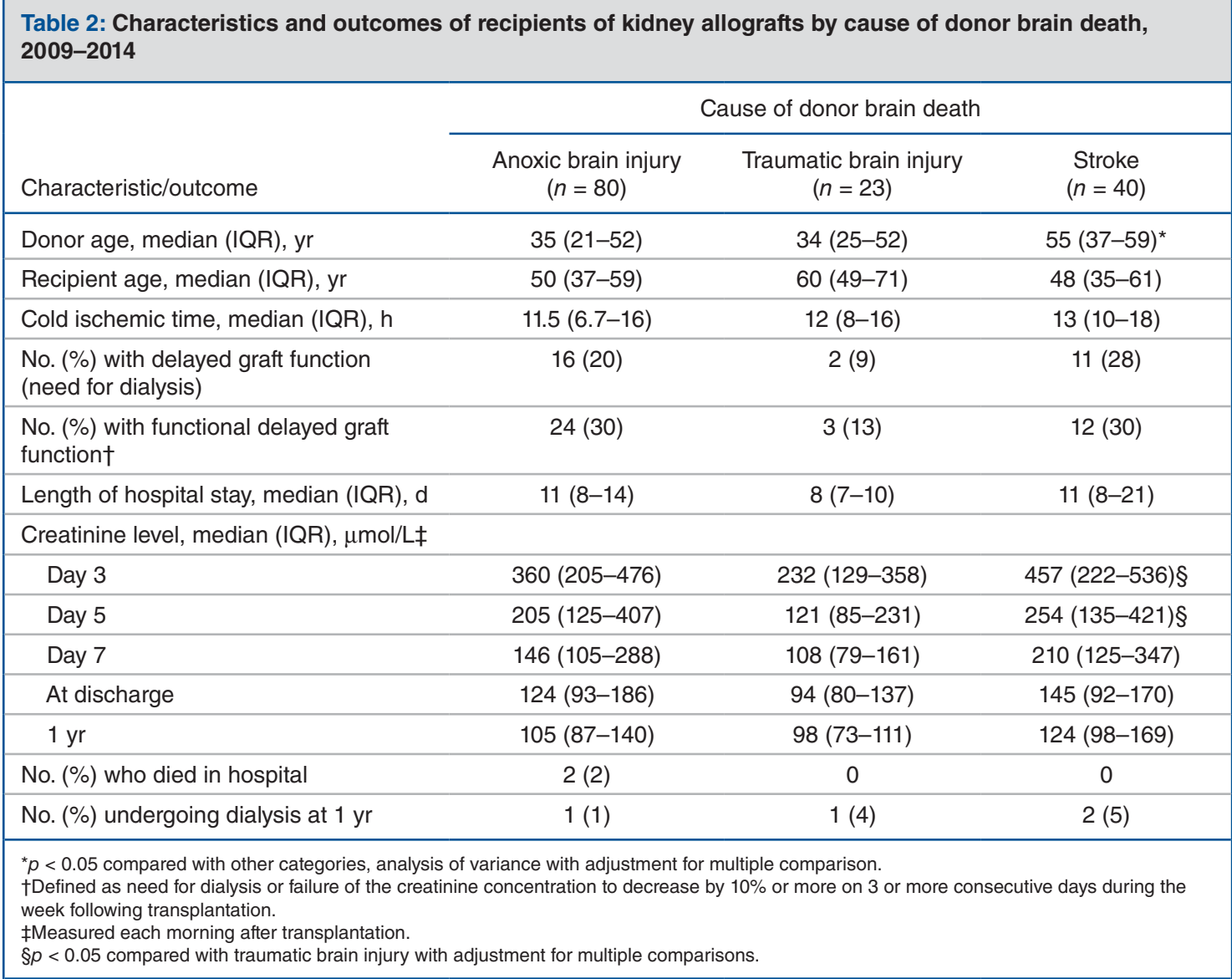


time of hospital discharge and at 1 year were lowest among recipients of kidneys from donors with traumatic brain injury than among recipients of kidneys from donors with other diagnoses, although the differences were statistically significant only in the first few days.

In recipients of kidneys from donors with anoxic brain injury, the median duration of cardiac arrest in the donor was 45 (interquartile range 21-69) minutes when delayed graft function occurred, compared with 30 (interquartile range $20-43)$ minutes without delayed graft function $(p=0.06)$. Delayed graft function occurred in 5/29 recipients (17\%) when cardiac arrest duration was less than 30 minutes, compared to $5 / 34(15 \%)$ and $6 / 12(50 \%)$ when the duration was $30-59$ minutes and 60 minutes or more, respectively $(p=$ 0.005 for comparison between $\geq 60 \mathrm{~min} v$. $<60 \mathrm{~min}$ ). At 1 year, $6(4.2 \%)$ of the 143 patients had died or were receiving dialysis.

\section{National data}

Across Canada, the number of brain-dead organ donors changed minimally between 2000 and 2013, remaining in the range of 12-14 donors per million population. The number of brain-dead donors with traumatic brain injury decreased from a maximum of 4.4 per million population in 2000-2002 to fewer than 3 per million population in 2009-2013. This decrement was offset by a threefold rise in the number of braindead donors with anoxic brain injury (from 0.7-1.1 per million population in 2000-2005 to 3.1 per million population in 2012-2013) (Figure 2).

The mean number of organs transplanted was higher from donors with traumatic brain injury than from those with other causes of neurologic death (Figure 3). This was true for each individual organ system (Table 3 ). Within each diagnostic category, the number of organs transplanted per donor increased over time. However, with the relative decline in donors with traumatic brain injury and increment in those with anoxic brain injury, the national average number of organs transplanted following neurologic determination of death remained stagnant, at 3.3-3.5 per donor.

The $\kappa$ statistic comparing categorization of the cause of neurologic death in our local data set with that submitted by our regional organ donation agency to CIHI was 0.77 (95\% confidence interval 0.71-0.84). All of the discrepancies were due to patients with traumatic brain injury, stroke or other causes of neurologic death who also had a cardiac arrest lasting more than 5 minutes.

\section{Interpretation}

Between 2003 and 2014, anoxic brain injury replaced traumatic brain injury and various forms of stroke as the most common cause of neurologic determination of death among organ donors in southern Alberta. Similarly, across Canada, the annual rate of organ donation from brain-dead donors following traumatic brain injury decreased by about $25 \%$, whereas the rate of organ donation following anoxic brain injury tripled.
Using national data, investigators in the United States showed that the proportion of organ donors with traumatic brain injury decreased from $45 \%-50 \% 10-15$ years ago to about $30 \%-35 \%$ more recently., Similarly, studies from Belgium showed that traumatic brain injury accounted for $35 \%-$ $40 \%$ of organ donors in $1997-2005$, compared to $25 \%$ in 2012-2013.,5 An unpublished report from the United Kingdom suggested that less than $10 \%$ of organ donors in recent years died following road traffic accidents. ${ }^{23}$ In a single-centre study from Quebec, the cause of death was traumatic brain injury in $27 \%$ of organ donors in 2000-2005, compared to $20 \%$ in 2006-2012. ${ }^{24}$

Conversely, the proportion of people who experience cardiac arrest in whom there is return of spontaneous circulation has increased over time, a trend that has been attributed, in part, to greater provision of bystander cardiopulmonary resuscitation and availability of automated external defibrillators. ${ }^{13-16}$ A previous study showed that people who had been resuscitated from a cardiac arrest accounted for a growing proportion of brain-injured patients admitted to intensive care units in our region. ${ }^{1}$ As suggested in consensus guidelines, clinicians may be delaying withdrawal of life-sustaining treatments to a greater degree, which, in turn, may provide more time for progression to neurologic determination of death. ${ }^{25,26}$ There may be regional differences in the proportion of donors in whom anoxic brain injury is the cause of neurologic death, but we found that overall trends were consistent across Canada. We did not find any differences in consent rates for organ donation based on the cause of neurologic death to account for the relative shift from traumatic brain injury to anoxic brain injury.

Donors with anoxic brain injury had, on average, a greater degree of organ injury than those with other conditions. Accordingly, the number of organs transplanted per donor was lower with anoxic brain injury than with other causes of neurologic death, even after adjustment for potentially confounding donor characteristics. With an increment in the proportion of donors with anoxic brain injury in our region, there was a corresponding decline, albeit not statistically significant, in the number of organs procured per donor.

The number of organs transplanted per donor across Canada was highest with traumatic brain injury but was similar for anoxic brain injury and stroke. Despite the relative decline in traumatic brain injury and concomitant increase in donors with anoxic brain injury, the average number of organs transplanted per brain-dead donor did not change, largely because of an increment within each individual diagnostic category. It is possible that transplantation programs have become more willing to accept "marginal" organs, including those from donors who experienced cardiac arrest. Because acceptance of the heart, lung and pancreas is lower than that of the kidney and liver, there is particular potential for increased use of the former organs.

Delayed graft function was uncommon in recipients of kidneys from donors with traumatic brain injury. In contrast, there was a high incidence of this complication among recipients of kidneys from donors who had sustained a cardiac 


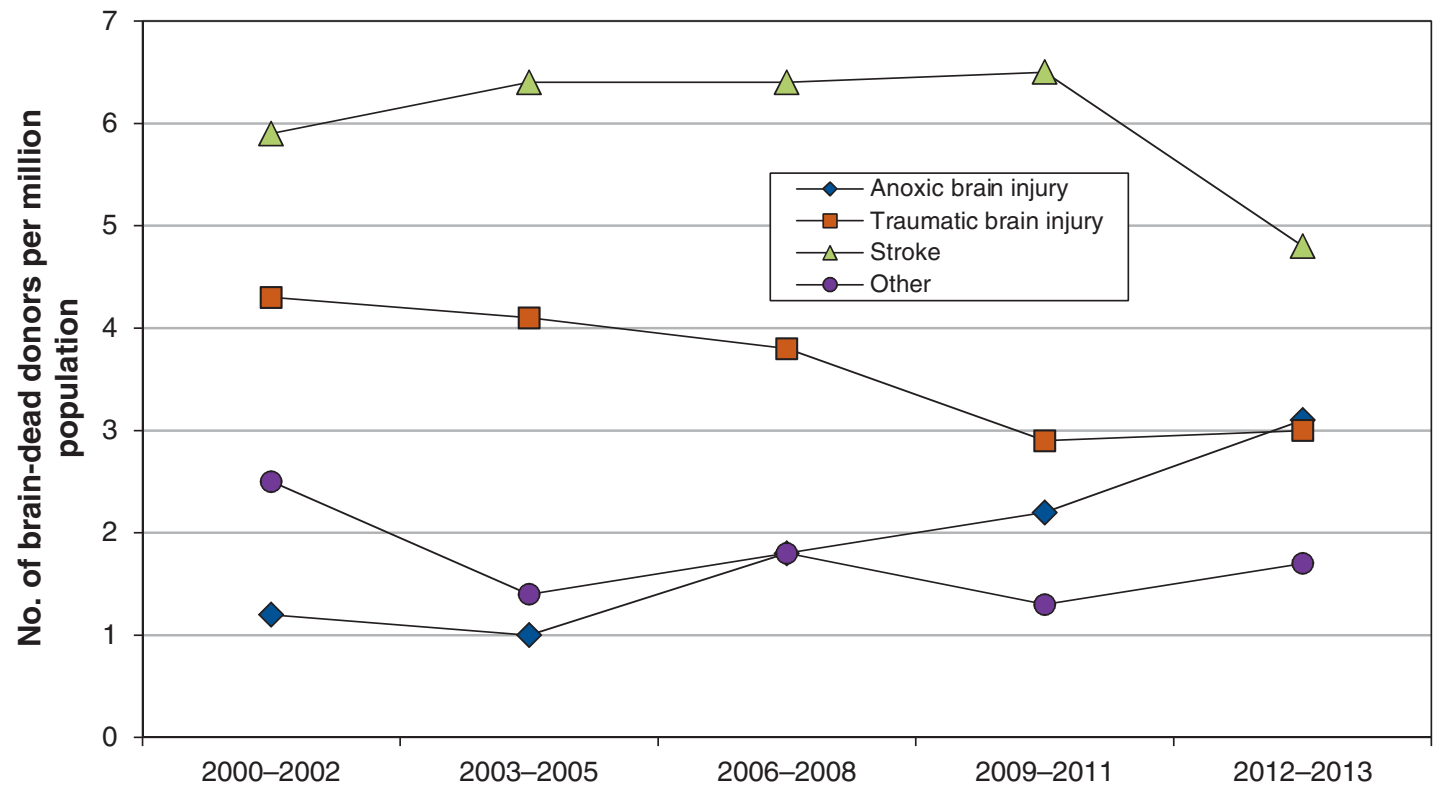

Figure 2: Temporal trends in the relative distribution of causes of neurologic death (brain death) among organ donors in Canada, 2000-2013; Quebec data available for 2000-2011 only.

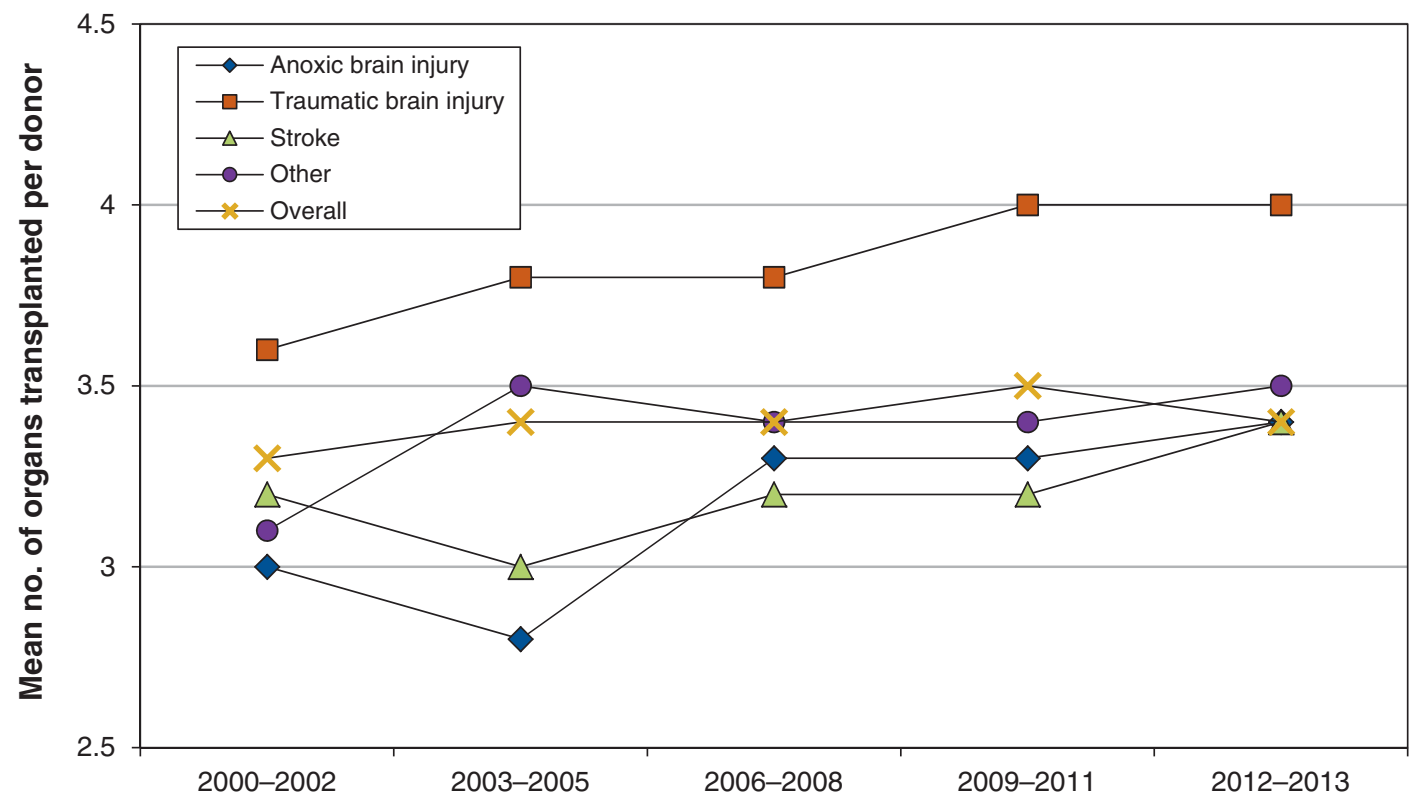

Figure 3: Temporal trends in the number of organs transplanted per brain-dead organ donor by diagnosis in Canada, 2000-2013 (Quebec data available for 2000-2011 only). 


\begin{tabular}{|lcccc|}
\hline \multicolumn{4}{|l|}{$\begin{array}{l}\text { Table 3: Proportion of brain-dead organ donors whose } \\
\text { organs were transplanted in Canada from 2000-2013 } \\
\text { (Quebec data available for 2000-2011 only), by cause of } \\
\text { death }\end{array}$} \\
\hline \multicolumn{5}{|c|}{ Cause of death; \% of donors } \\
\cline { 2 - 5 } & $\begin{array}{c}\text { Traumatic } \\
\text { brain injury }\end{array}$ & $\begin{array}{c}\text { Anoxic } \\
\text { brain injury }\end{array}$ & Stroke & Other \\
\hline Kidney & 94 & 84 & 86 & 84 \\
\hline Liver & 86 & 83 & 83 & 80 \\
\hline Lung & 37 & 26 & 32 & 38 \\
\hline Heart & 49 & 29 & 23 & 38 \\
\hline Pancreas & 36 & 25 & 21 & 26 \\
\hline *Whole pancreas or islet cells. & & & \\
\hline
\end{tabular}

arrest, especially when the arrest duration exceeded 60 minutes. Delayed graft function is associated with a higher incidence of acute rejection, eventual graft failure and long-term mortality as well as higher cost. ${ }^{27,28}$ Interventions aimed at reducing delayed graft function, such as systemic hypothermia in donors, pulsatile machine perfusion and adjustment of immunosuppressive regimens in recipients, may be particularly important when kidneys are procured from donors whose organs are at high risk for delayed graft function, such as those with prolonged cardiac arrest..$^{28-30}$

Authors of previous small studies have assessed organ injury in brain-dead donors who experienced cardiac arrest. $^{31-34}$ Those with anoxic brain injury were generally reported to have greater hemodynamic instability and higher liver enzymes, and fewer organs were procured from these donors. However, outcomes in recipients of organs from donors with anoxic brain injury were not necessarily worse than with other diagnoses. ${ }^{35-41}$ Despite the high rate of delayed graft function with prolonged cardiac arrest, few patients in our study required dialysis after 1 year. In addition, although there was a consistent trend toward lower creatinine concentrations in recipients of kidneys from donors with traumatic brain injury compared to those who received kidneys from donors with anoxic brain injury or stroke immediately in the days following transplantation, the differences were not statistically significant after 1 year.

Achievement of certain "donor management goals" before organ procurement has been associated with a larger number of organs transplanted. ${ }^{42-44}$ Based on our observations, consistent achievement of donor management goals may be less realistic for donors with anoxic brain injury, especially those sustaining prolonged cardiac arrest. For example, despite routine adherence to Canadian guidelines, ${ }^{18}$ significantly fewer donors with anoxic brain injury achieved the donor management goals of $\mathrm{P}_{\mathrm{a}} \mathrm{O}_{2} / \mathrm{F}_{1} \mathrm{O}_{2}$ greater than $300 \mathrm{~mm} \mathrm{Hg}$ or urine output greater than $0.5 \mathrm{~mL} / \mathrm{kg}$ per hour. ${ }^{42,43}$ Nevertheless, adoption of Canadian recommendations for organ donor management may be one reason why the number of organs transplanted per donor has increased nationally for each individual cause of neurologic death. ${ }^{18}$

\section{Limitations}

Our study is limited by its retrospective design, although most data were collected prospectively. Data from CIHI underestimates anoxic brain injury as a cause of neurologic death, since only 1 diagnostic code can be assigned per donor. For example, if a donor with traumatic brain injury or stroke also had a prolonged cardiac arrest, this information would not be recorded in the CIHI data set. A single reviewer adjudicated the causes of neurologic death for our study. However, apart from cases in which there was more than 1 cause of death, there was excellent agreement with the cause of death for southern Alberta organ donors in the CIHI database. Data for 2014-2016 were not yet available from CIHI, and we did not have 2012-2013 data from Quebec. Finally, measures of organ injury were not available from CIHI, such that we could not assess them using national data.

\section{Conclusion}

The epidemiologic characteristics of neurologic death in Canada changed between 2003 and 2014, with a relative decline in the proportion of donors with traumatic brain injury and an increment in those with anoxic brain injury. Because fewer organs are procured and transplanted from the latter group, this epidemiologic shift has contributed to stagnancy in the total number of organs available for transplantation. Outcomes are favourable when organs from wellselected brain-dead donors with anoxic brain injury are transplanted, although prolonged cardiac arrest in the donor is associated with a higher incidence of delayed graft function, which may affect longer-term outcomes. Future research should develop additional strategies aimed at optimizing use of organs from brain-dead donors.

\section{References}

1. Kramer AH, Zygun DA, Doig CJ, et al. Incidence of neurologic death among patients with brain injury: a cohort study in a Canadian health region. CMAJ 2013;185:E838-45.

2. Callahan DS, Kim D, Bricker S, et al. Trends in organ donor management: 2002 to 2012. 7 Am Coll Surg 2014;219:752-6.

3. Saidi RF, Markmann JF, Jabbour N, et al. The faltering solid organ donor pool in the United States (2001-2010). World 7 Surg 2012;36:2909-13.

4. Van Gelder F, Delbouille MH, Vandervennet M, et al. An 11-year overview of the Belgian donor and transplant statistics based on a consecutive yearly data follow-up and comparing two periods: 1997 to 2005 versus 2006 to 2007. Transplant Proc 2009;41:569-71.

5. Desschans B, Evrard P. Organ donation and transplantation statistics in Belgium for 2012 and 2013. Transplant Proc 2014;46:3124-6.

6. Johnson RJ, Bradbury LL, Martin K, et al.; UK Transplant Registry. Organ donation and transplantation in the UK - the last decade: a report from the UK national transplant registry. Transplantation 2014;97:S1-27.

7. Kompanje EJ, de Groot YJ, Bakker J. Is organ donation from brain dead donors reaching an inescapable and desirable nadir? Transplantation 2011;91: 1177-80.

8. Kramer AH, Deis N, Ruddell S, et al. Decompressive craniectomy in patients with traumatic brain injury: Are the usual indications congruent with those evaluated in clinical trials? Neurocrit Care 2016;25:10-9.

9. Schirmer CM, Hoit DA, Malek AM. Decompressive hemicraniectomy for the treatment of intractable intracranial hypertension after aneurysmal subarachnoid hemorrhage. Stroke 2007;38:987-92.

10. Fung C, Murek M, Z'Graggen WJ, et al. Decompressive hemicraniectomy in patients with supratentorial intracerebral hemorrhage. Stroke 2012;43: 3207-11.

11. Schwab S, Steiner T, Aschoff A, et al. Early hemicraniectomy in patients with complete middle cerebral artery infarction. Stroke 1998;29:1888-93.

12. Head injuries in Canada: a decade of change (1994-1995 to 2003-2004). Ottawa: Canadian Institute of Health Information; 2006. Available: https://secure.cihi. ca/free_products/ntr_head_injuries_2006_e.pdf (accessed 2015 Nov. 2). 
13. Chan PS, McNally B, Tang F, et al. Recent trends in survival from out-ofhospital cardiac arrest in the United States. Circulation 2014;130:1876-82.

14. Daya MR, Schmicker RH, Zive DM, et al. Out-of-hospital cardiac arrest survival improving over time: results from the Resuscitation Outcomes Consortium (ROC). Resuscitation 2015;91:108-15.

15. McNally B, Robb R, Mehta M, et al. Out-of-hospital cardiac arrest surveillance - Cardiac Arrest Registry to Enhance Survival (CARES), United States, October 1, 2005-December 31, 2010. MMWR Surveill Summ 2011; 60:1-19.

16. Kitamura T, Iwami T, Kawamura T, et al.; Implementation Working Group for the All-Japan Utstein Registry of the Fire and Disaster Management Agency. Nationwide public-access defibrillation in Japan. $N$ Engl 7 Med 2010;362:994-1004.

17. Geri G, Mongardon N, Daviaud F, et al. Neurological consequences of cardiac arrest: Where do we stand? Ann Fr Anesth Reanim 2014:33:98-101.

18. Shemie SD, Ross H, Pagliarello J, et al. Organ donor management in Canada: recommendations of the forum on Medical Management to Optimize Donor Organ Potential. CMA7 2006;174:S13-32.

19. Busl KM, Greer DM. Hypoxic-ischemic brain injury: pathophysiology, neuropathology and mechanisms. NeuroRebabilitation 2010;26:5-13.

20. Moore J, Shabir S, Chand S, et al. Assessing and comparing rival definitions of delayed renal allograft function for predicting subsequent graft failure. Transplantation 2010;90:1113-6.

21. Tukey JW. Comparing individual means in the analysis of variance. Biometrics 1949:5:99-114.

22. Armitage P. Tests for linear trends in proportions and frequencies. Biometrics 1954;10:417-51

23. Changing donor characteristics. Bristol (UK): NHS Blood and Transplant; 2012. Available: www.odt.nhs.u/uk-transplant-registry/slides-presentations -for-download/ (accessed 2016 July 20).

24. Hassanain M, Simoneau E, Doi SA, et al. Trends in brain-dead organ donor characteristics: a 13-year analysis. Can 7 Surg 2016;59:154-60.

25. Nolan JP, Soar J, Cariou A, et al. European Resuscitation Council and European Society of Intensive Care Medicine Guidelines for Post-resuscitation Care 2015: Section 5 of the European Resuscitation Council Guidelines for Resuscitation 2015. Resuscitation 2015;95:202-22.

26. Callaway CW, Donnino MW, Fink EL, et al. Part 8: Post-cardiac arrest care: 2015 American Heart Association Guidelines Update for Cardiopulmonary Resuscitation and Emergency Cardiovascular Care. Circulation 2015;132: S465-82.

27. Rosenthal JT, Danovitch GM, Wilkinson A, et al. The high cost of delayed graft function in cadaveric renal transplantation. Transplantation 1991;51:1115-8.

28. Siedlecki A, Irish W, Brennan DC. Delayed graft function in the kidney transplant. Am 7 Transplant 2011;11:2279-96.

29. Niemann CU, Feiner J, Swain S, et al. Therapeutic hypothermia in deceased organ donors and kidney-graft function. N Engl 7 Med 2015;373:405-14.

30. Bathini V, McGregor T, McAlister VC, et al. Renal perfusion pump vs cold storage for donation after cardiac death kidneys: a systematic review. 7 Urol 2013;189:2214-20.

31. Mercatello A, Roy P, Ng-Sing K, et al. Organ transplants from out-of-hospital cardiac arrest patients. Transplant Proc 1988;20:749-50.

32. Delaunay L, Denis V, Darmon PL, et al. Initial cardiac arrest is a risk factor for failure of organ procurement in brain-dead patients. Transplant Proc 1996; 28:2894.

33. Wilson DJ, Fisher A, Das K, et al. Donors with cardiac arrest: improved organ recovery but no preconditioning benefit in liver allografts. Transplantation 2003;75:1683-7.

34. Adrie C, Haouache H, Saleh M, et al. An underrecognized source of organ donors: patients with brain death after successfully resuscitated cardiac arrest. Intensive Care Med 2008;34:132-7.
35. Ali AA, Lim E, Thanikachalam M, et al. Cardiac arrest in the organ donor does not negatively influence recipient survival after heart transplantation. Eur 7 Cardiothorac Surg 2007;31:929-33.

36. Matsumoto CS, Kaufman SS, Girlanda R, et al. Utilization of donors who have suffered cardiopulmonary arrest and resuscitation in intestinal transplantation. Transplantation 2008;86:941-6.

37. Levesque E, Hoti E, Khalfallah M, et al. Impact of reversible cardiac arrest in the brain-dead organ donor on the outcome of adult liver transplantation. Liver Transpl 2011;17:1159-66.

38. Quader MA, Wolfe LG, Kasirajan V. Heart transplantation outcomes from cardiac arrest-resuscitated donors. 7 Heart Lung Transplant 2013;32:1090-5.

39. Castleberry AW, Worni M, Osho AA, et al. Use of lung allografts from brain-dead donors after cardiopulmonary arrest and resuscitation. Am 7 Respir Crit Care Med 2013;188:466-73.

40. Hoyer DP, Paul A, Saner F, et al. Safely expanding the donor pool: brain dead donors with history of temporary cardiac arrest. Liver Int 2015;35: 1756-63.

41. Sandroni C, Adrie C, Cavallaro F, et al. Are patients brain-dead after successful resuscitation from cardiac arrest suitable as organ donors? A systematic review. Resuscitation 2010;81:1609-14.

42. Patel MS, Zatarain J, De La Cruz S, et al. The impact of meeting donor management goals on the number of organs transplanted per expanded criteria donor. FAMA Surg 2014;149:969-75.

43. Malinoski DJ, Patel MS, Daly MC, et al.; UNOS Region 5 DMG Workgroup. The impact of meeting donor management goals on the number of organs transplanted per donor: results from the United Network for Organ Sharing Region 5 prospective donor management goals study. Crit Care Med 2012;40:2773-80.

44. Kotloff RM, Blosser S, Fulda GJ, et al.; Society of Critical Care Medicine/ American College of Chest Physicians/Association of Organ Procurement Organizations Donor Management Task Force. Management of the potential organ donor in the ICU: Society of Critical Care Medicine/American College of Physicians/Association of Organ Procurement Organizations Consensus Statement. Crit Care Med 2015;43:1291-325.

Affiliations: Departments of Critical Care Medicine (Kramer, Doig) and Clinical Neurosciences (Kramer), University of Calgary; Southern Alberta Organ and Tissue Donation Program (Kramer, Baht); Department of Community Health Sciences (Doig), University of Calgary, Calgary, Alta.

Contributors: Andreas Kramer conceived and designed the study, assisted in data acquisition, performed the data analysis and interpretation, and drafted the manuscript. Ryan Baht assisted in data acquisition, contributed to drafting the manuscript and revised the manuscript for important intellectual content. Christopher Doig assisted with data analysis and interpretation, contributed to drafting the manuscript and revised the manuscript for important intellectual content. All of the authors approved the final version to be published and agreed to act as guarantors of the work.

Funding: This study was performed without dedicated funding. Andreas Kramer receives salary support from Alberta Health Services in his role as Medical Director of the Southern Alberta Organ and Tissue Donation Program.

Supplemental information: For reviewer comments and the original submission of this manuscript, please see www.cmajopen.ca/content/5/1/ E19/suppl/DC1 